\begin{tabular}{|c|c|c|c|c|c|c|}
\hline \multirow{4}{*}{ Impact Factor: } & ISRA (India) & $=3.117$ & SIS (USA) & $=0.912$ & ICV (Poland) & $=6.630$ \\
\hline & ISI (Dubai, UAE & $=0.829$ & РИНЦ (Russia & $=0.156$ & PIF (India) & $=1.940$ \\
\hline & GIF (Australia) & $=0.564$ & ESJI (KZ) & $=\mathbf{5 . 0 1 5}$ & IBI (India) & $=4.260$ \\
\hline & JIF & $=1.500$ & SJIF (Morocco & $=5.667$ & & \\
\hline
\end{tabular}

\begin{tabular}{|c|c|}
\hline $\begin{array}{l}\text { SOI: } 1.1 / \overline{\mathrm{S}} \\
\text { International } \mathrm{S} \\
\text { Theoretical } \mathbf{\&}\end{array}$ & $\begin{array}{l}\frac{\Gamma A S}{\text { DOI: }} 10.15863 / \mathrm{TAS} \\
\text { cientific Journal } \\
\text { Applied Science }\end{array}$ \\
\hline p-ISSN: 2308-4944 (print) & e-ISSN: 2409-0085 (online) \\
\hline Year: 2018 & Volume: 68 \\
\hline Published: 14.12 .2018 & http://T-Science.org \\
\hline
\end{tabular}

SECTION 31. Economic research, finance, innovation, risk management.
QR - Issue

QR - Article

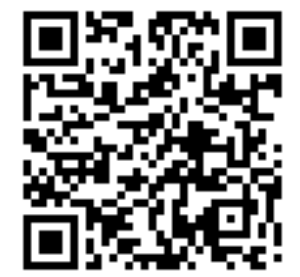

E.V. Bergal candidate of economic sciences, associate professor Kuban state university, Russia, Krasnodar bergall@bk.ru

K.S. Merzlikina student

Kuban state university, Russia, Krasnodar merzlikina.ksu@gmail.com

\title{
DEVELOPMENT OF IT-TECHNOLOGIES IN THE SYSTEM OF TAX ADMINISTRATION
}

\begin{abstract}
The article considers the issues of tax administration and control through IT-technologies in the conditions of digitalization of the economy, analyzes the results of innovative reforms in the field of taxation. The authors highlighted some problems in the functioning of software: the lack of flexibility in relation to changing legislation; significant upgrade costs; lack of access to analytics obtained during use of programs; complexity for perception by certain categories of taxpayers. According to the authors, simultaneous use of software with the mechanism of tax agreements and information visualization tools will improve the efficiency of applying ITtechnologies in the tax administration system. In the case of successful implementation of these proposals, the authors see it possible to transfer issues related to the disclosure of a part of information on the basis of a paid subscription to the tax authorities.

Key words: tax control, tax administration, digital economy, software of the Federal Tax Service, automated information system "Tax-3", automated system for monitoring VAT, IT-technologies.

Language: Russian

Citation: Bergal, E. V., \& Merzlikina, K. S. (2018). Development of IT-technologies in the system of tax administration. ISJ Theoretical \& Applied Science, 12 (68), 65-69.

Soi: http://s-o-i.org/1.1/TAS-12-68-13 Doi: crossef https://dx.doi.org/10.15863/TAS.2018.12.68.13

\section{РАЗВИТИЕ ІТ-ТЕХНОЛОГИЙ В СИСТЕМЕ НАЛОГОВОГО АДМИНИСТРИРОВАНИЯ}

Аннотация: В статье рассматриваются вопросы налогового администрирования и контроля посредством IT-технологий в условиях ичифровизации экономики, анализируются результаты инновационных преобразований в сфере налогообложения. Авторами выделен ряд проблем функционирования программных средств: отсутствие гибкости по отношению к меняюшемуся законодательству; значительные расходы на обновление; отсутствие доступа к аналитике, получаемой в прочессе использования; сложность для восприятия отдельными категориями налогоплательщиков. По мнению авторов, дополнение программных средств механизмом налоговых соглашений и инструментами визуализации информации позволят повысить эффективность применения IT-технологий в системе налогового администрирования. В случае успешной реализачии данных предложений авторы видят возможным передачу в ведение налоговых органов вопросов, связанных с раскрытием части информации на основе платной подписки.

Ключевые слова: налоговый контроль, налоговое администрирование, циифровая экономика, программные средства Федеральной налоговой службы, автоматизированная информационная система «Налог-3», автоматизированная система контроля НДС, IT-технологии.
\end{abstract}

Introduction

Активное развитие цифровой экономики, IT- индустрии и инновационные преобразования в сфере налогового контроля осуществляются в 


\begin{tabular}{|c|c|c|c|c|c|c|}
\hline \multirow{4}{*}{ Impact Factor: } & ISRA (India) & $=3.117$ & SIS (USA) & $=0.912$ & ICV (Poland) & $=6.630$ \\
\hline & ISI (Dubai, UAE & $=0.829$ & РИНЦ (Russia & $=0.156$ & PIF (India) & $=1.940$ \\
\hline & GIF (Australia) & $=0.564$ & ESJI (KZ) & $=\mathbf{5 . 0 1 5}$ & IBI (India) & $=4.260$ \\
\hline & JIF & $=1.500$ & SJIF (Morocco & $=5.667$ & & \\
\hline
\end{tabular}

рамках реализации государственной программы «Информационное общество (2011-2020 годы)» и Федерального закона от 27.07.2010 № 210-Ф3 «Об организации предоставления государственных и муниципальных услуг» [1]. Также за последние 10 лет был принят ряд важных организационных и технологических решений, которые позволили, с одной стороны, улучшить собираемость доходов бюджета, а с другой, повысить степень доверия и взаимопонимания между налоговыми органами и налогоплательщиками [2, 3, 4]. В результате Федеральная налоговая служба России (далее ФНС) является лидером оказания госуслуг в электронном виде, занимает 3 место в рейтинге государственных сайтов Gosmonitor.ru и имеет премию Рунета в номинации «Государство и общество» 2015. Это и другие показатели эффективности работы ФНС (количество выездных налоговых проверок, величина собираемых налогов, количество поступающих электронных документов и т.д.) подтверждают, что ІТ-технологии в рамках работы ФНС позволяют обеспечивать добровольное соблюдение налогоплательщиками налогового законодательства [9]. Таким образом, реализация требований цифровизации экономики предопределила актуальность темы исследования.

\section{Materials and Methods}

Теоретические и организационно-правовые аспекты внедрения различного рода программных средств в деятельность ФНС России и онлайн-инструментов для налогоплательщиков исследованы в трудах таких российских учёных, как Е.Е. Смирнова, А.С. Адвокатова, Д.В. Наумчев, Д.А. Селеверстов, О.А. Соболева, Н.А. Мячина и др. [9, 5, 6]. Однако в связи с тем, что современные технологии (одновременно с правовыми механизмами регулирования) непрерывно развиваются и совершенствуются, имеется потребность исследовать их более глубоко с учетом осуществляющихся трансформаций.

В ходе исследования проанализированы результаты инновационных преобразований в сфере налогового контроля. Обращаем внимание на то, что ФНС целенаправленно ушла от тотального контроля налогоплательщиков как низкоэффективного инструмента. Сегодня ФНС осуществляет свою деятельность, основываясь на методах риск-анализа и предварительного контроля, точечно выбирая объекты для налоговых проверок посредством соответствующих программных продуктов и сервисов. Эффект от данного подхода - это снижение количества проверок и, следовательно, административной нагрузки на бизнес при одновременном повышении эффективности контрольной функции налоговых органов. В анализируем периоде количество проверок сократилось почти в 9 раз, что наглядно представлено на рисунке 1 [5].

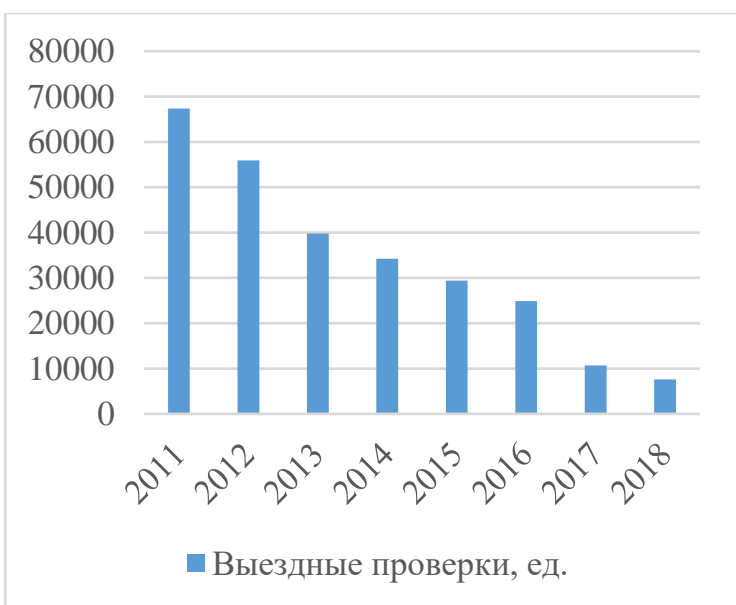

Рисунок 1 - Динамика количества выездных налоговых проверок в период 2011 - 2018 гг. Источник: https://www.nalog.ru/rn77/related activities/statistics and analytics/

Налогоплательщики активно используют сервисы, предоставляемые официальным сайтом ФНС России. По данным ФНС за три года количество пакетов документов, направленных на государственную регистрацию через
Интернет, увеличилось в 2,5 раза (рис. 2). Посещаемость сайта ФНС составляет порядка 90 млн. чел. в год, что подтверждает эффективность работы системы электронного документооборота. 


\begin{tabular}{llllll} 
& ISRA (India) $=\mathbf{3 . 1 1 7}$ & SIS (USA) $=\mathbf{0 . 9 1 2}$ & ICV (Poland) & $=\mathbf{6 . 6 3 0}$ \\
Impact Factor: & ISI (Dubai, UAE) $=\mathbf{0 . 8 2 9}$ & PUHL (Russia) $=\mathbf{0 . 1 5 6}$ & PIF (India) & $=\mathbf{1 . 9 4 0}$ \\
& GIF (Australia) $=\mathbf{0 . 5 6 4}$ & ESJI (KZ) & $\mathbf{5 . 0 1 5}$ & IBI (India) & $\mathbf{4 . 2 6 0}$ \\
& JIF & $\mathbf{1 1 . 5 0 0}$ & SJIF (Morocco) $=\mathbf{5 . 6 6 7}$ & & \\
\hline
\end{tabular}

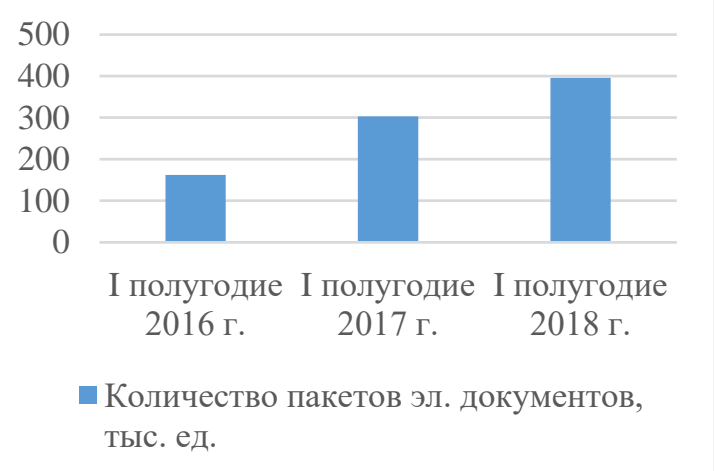

Рисунок 2 - Динамика количества пакетов электронных документов, направленных на государственную регистрацию через Интернет за I полугодие 2018 года и соответствующие периоды 2016 - 2017 гг. Источник: https://www.nalog.ru/rn77/related_activities/statistics_and_analytics/

ФНС удалось достичь значительных результатов в сфере совершенствования механизмов налогового администрирования.

Прежде всего - это переход на автоматизированную информационную систему «Налог-3» - систему обработки налоговой информации по четко заданным алгоритмам в автоматическом режиме, т.е. без участия налогового инспектора. Обработка включает расчет налогов, вычисление показателей для карточек расчетов с бюджетами, формирование и направление документов налогоплательщику, предварительный отбор налогоплательщиков для проверки и другие функции. «Налог-3» позволил снизить трудоемкость выполнения бизнеспроцессов посредством внедрения более дружественного интерфейса, сделать использование информации комплексным, исключить дублирование, повысить открытость налоговых органов и уровень внутреннего контроля над их деятельностью, использовать централизованную нормативно-справочную информацию. Основное преимущество АИС
«Налог-3» - это «Налоговый автомат».

Также следует отметить внедрение в практическую деятельность ФНС системы АСКНДС-3, которая обеспечивают контроль деклараций по НДС и построена на процессинговом риск-анализе [7]. Система разработана для автоматизации процесса выявления налогоплательщиков, неправомерно предъявивших НДС к вычету или не исчисливших НДС к уплате в бюджет. Система позволяет выявлять расхождения в представленных налоговых декларациях и направлять налогоплательщикам требования о предоставлении пояснений, уточненной декларации, а также доначислении налога, что способствует сокращению числа субъектов теневого сектора экономики. Эффективность данного механизма легко проанализировать, обратившись к динамике поступлений налога на добавленную стоимость в консолидированный бюджет РФ, представленной на рисунке 3 [7].

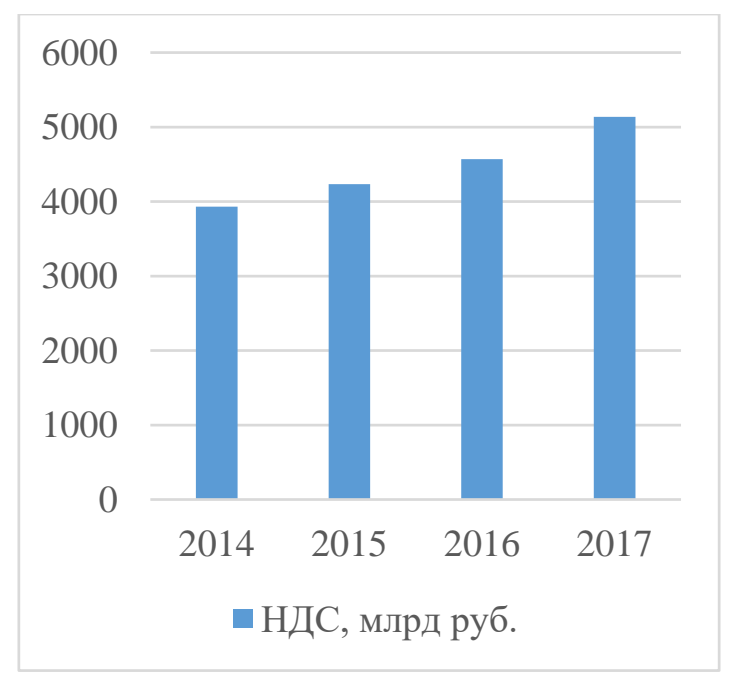

Рисунок 3 - Динамика поступлений НДС в консолидированный бюджет РФ в 2014 - 2017 гг. Источник: https://www.minfin.ru/ru/statistics/conbud/ 


\begin{tabular}{|c|c|c|c|c|c|c|}
\hline \multirow{4}{*}{ Impact Factor: } & ISRA (India) & $=3.117$ & SIS (USA) & $=0.912$ & ICV (Poland) & $=6.630$ \\
\hline & ISI (Dubai, UAE & $=0.829$ & РИНЦ (Russia) & $=0.156$ & PIF (India) & $=1.940$ \\
\hline & GIF (Australia) & $=0.564$ & ESJI (KZ) & $=5.015$ & IBI (India) & $=4.260$ \\
\hline & JIF & $=1.500$ & SJIF (Morocco) & $=5.667$ & & \\
\hline
\end{tabular}

Согласно приведенным данным в рамках анализируемого периода величина налоговых поступлений неуклонно росла.

Другой значимый результат работы ФНС это порядка 40 интерактивных онлайн-сервисов, предлагаемых налогоплательщикам. Например, заполнение налоговых платежных поручений, оформление заявки на получение ИНН, получение информации о пенсионных отчислениях, долгах по налогам и т.д. Среди наиболее социально значимых следует выделить «Личный кабинет налогоплательщика». Во многом именно за счет введения таких сервисов значительное число налогоплательщиков оценивает работу ФНС как удовлетворительную (их доля составляет $84,1 \%$ ).

Вместе с тем ФНС еще не может полностью отказаться от «бумажной волокиты» внутри своих подразделений. Отчасти это связано с проблемами программного обеспечения.

Так, к недостаткам АИС «Налог-3» и АСКНДС-3 следует отнести отсутствие гибкости к часто меняющемуся законодательству в сфере налогообложения и доступа к получаемой в ходе функционирования систем аналитике. Говоря о гибкости, нельзя не отметить тот факт, что частые обновления программных инструментов с учетом нововведений в налоговых нормативноправовых актах ведут за собой существенные расходы бюджетных средств. По данным сайта госзакупок только разработка, внедрение и техническое сопровождение АИС «Налог-3» стоило ФНС около 4,7 млрд руб. Можно предположить, что и ежегодная адаптация программного обеспечения к меняющемуся законодательству так же существенно сказывается на расходовании средств. Следующая проблема касается онлайн-сервисов для налогоплательщиков, представленных на официальном сайте ФНС России. Несмотря на наличие обучающих видеороликов, отдельным категориям налогоплательщиков сложно взаимодействовать с данными инструментами.

Для решения указанных проблем мы видим следующее.
Во-первых, предлагается упростить механизм технического сопровождения основных программных продуктов, используемых в работе $\Phi H C$.

Во-вторых, обеспечить доступ заинтересованных субъектов бизнеса на условиях платной подписки к аналитической информации о деятельности компаний, получаемой в ходе администрирования налогов. ФНС имеет ресурсы для представления проверенной достоверной информации в формате, пригодном для восприятия. Подобное мероприятие способствовало бы повышению эффективности принятия управленческих решений вследствие представления собранного по налогоплательщику массива данных в читаемой и легко анализируемой форме, например, в виде краткого отчёта с автоматически рассчитанными ключевыми показателями, а также увеличению доходной части бюджета за счет платного доступа к данным.

В-третьих, увеличить эффект от предоставления налогоплательщикам широкого спектра онлайн-услуг могло бы их сочетание с механизмом налоговых соглашений, который предполагает консультирование налогоплательщиков по вопросам отдельных налоговых платежей или оценку фактических ситуаций в связи с проведением фискального контроля.

\section{Conclusion}

Исходя из полученных результатов, можно сделать вывод о том, что ФНС сегодня - это предприяте обслуживающего типа, предоставляющее достаточно широкий спектр услуг, перерабатывающее существенные объемы информации и располагающее всеми ресурсами для прямого взаимодействия с налогоплательщиками и построения максимально эффективной системы налогового администрирования в РФ. Предлагаемые меры совершенствования позволят сделать работу ФНС более прозрачной для налогоплательщиков, обеспечат снижение налоговых рисков.

\section{References:}

1. (2010). Federalnyj zakon ot 27.07.2010 № 210$F Z \ll O b$ organizacii predostavleniya gosudarstvennyh $i$ municipalnyh uslug». Retrieved 2018, from http://base.garant.ru/12177515/
2. (2014). Prikaz FNS Rossii ot 04.12.2014 № MMV-7-1/612@ «Ob utverzhdenii Strategicheskoj karty FNS Rossii na 2014 2018 gg.». Retrieved 2018, from http://base.garant.ru/70816294/ 


\begin{tabular}{|c|c|c|c|c|c|c|}
\hline \multirow{4}{*}{ Impact Factor: } & ISRA (India) & $=3.117$ & SIS (USA) & $=0.912$ & ICV (Poland) & $=6.630$ \\
\hline & ISI (Dubai, UAE & $=0.829$ & РИНЦ (Russia) & $=0.156$ & PIF (India) & $=1.940$ \\
\hline & GIF (Australia) & $=0.564$ & ESJI (KZ) & $=\mathbf{5 . 0 1 5}$ & IBI (India) & $=4.260$ \\
\hline & JIF & $=1.500$ & SJIF (Morocco) & $=5.667$ & & \\
\hline
\end{tabular}

3. (2015). Prikaz FNS Rossii ot 13.02.2015 № MMV-7-6/68@«O provedenii opytnoj i opytnopromyshlennoj ehkspluatacii programmnyh sredstv, obespechivayushchih avtomatizaciyu perekrestnyh proverok, realizuyushchih funkcii kameral'noj nalogovoj proverki nalogovyh deklaracij po NDS na osnove svedenij iz knig pokupok, knig prodazh $i$ zhurnalov ucheta vystavlennyh $i$ poluchennyh schetov-faktur» Retrieved 2018, from http://base.garant.ru/70870804/

4. (2013). Prikaz FNS Rossii ot 13.06.2013 № MMV-7-6/196@ «Ob utverzhdenii

Metodicheskih rekomendacij po organizacii ehlektronnogo dokumentooborota mezhdu nalogovymi organami $i$ nalogoplatel'shchikami pri informacionnom obsluzhivanii $i$ informirovanii nalogoplatelshchikov $v$ ehlektronnoj forme po telekommunikacionnym kanalam svyazi». Retrieved 2018, from http://docs.cntd.ru/document/499027199

5. Advokatova, A. S. (2018). Razvitie modelej nalogovogo kontrolya kak faktora snizheniya urovnya tenevyh ehkonomicheskih processov $\mathrm{v}$ usloviyah cifrovizacii. Ekonomika. Nalogi. Pravo, № 5, 136-145.

6. Naumchev, D. V., \& Seleverstov, D. A. (2011). Sistema ehlektronnogo dokumentooborota FNS Rossii: mezhdu proshlym i budushchim. Nalogovaya politika i praktika, № 8, $18-21$.

7. Predeus, N. V. (2018). Informacionnye tekhnologii nalogovogo kontrolya NDS. Faktory uspeha, № 1(10), 76 - 79.

8. Ryabinina, E. V. (2016). Prioritetnoe napravlenie deyatel'nosti FNS Rossii - Internetservisy. Sovremennye tendencii razvitiya nauki $i$ tekhnologij, № 9-3, $124-126$.

9. Smirnova, E. E. (2018). Ocenka ehffektivnosti deyatel'nosti nalogovyh organov $\mathrm{v}$ usloviyah cifrovizacii ehkonomiki. Ekonomika. Nalogi. Pravo, № 2, 149-154.

10. Totikova, T. E. (2016). Modernizaciya sistem nalogovogo administrirovaniya $\mathrm{v}$ zarubezhnyh stranah: analiz osnovnyh tendencij. Izvestiya Saratovskogo universiteta. Novaya seriya. Seriya Ekonomika. Upravlenie. Pravo, № 4, 445-448. 